\title{
Aspectos gerais de infecções por bactérias do gênero Salmonella, um problema de saúde pública e animal
}

General aspects of infections by bacteria of the genus Salmonella, a public and animal health problem

Aspectos generales de las infecciones por bacterias del género Salmonella, un problema de salud pública y animal

\section{Resumo}

Objetivo: O objetivo do trabalho foi evidenciar as características gerais da Salmonella spp. quanto à fisiopatologia, dando enfoque nas formas de controle e correlacionar a higiene com a segurança alimentar. Metodologia: foi realizada uma busca nas bases de dados bibliográficas: Science Direct, Google acadêmico, Pubmed e Scielo, para selecionar artigos publicados entre os anos de 2011-2020. Os termos utilizados foram: Infecções alimentares, Salmonella spp, segurança alimentar, carne de frango, associados entre si nos idiomas português e inglês. Resultados: O processo infeccioso por Salmonella spp. é complexo, a bactéria é capaz de produzir mais de 400 proteínas que provocam reações inflamatórias, mesmo que não estejam hospedadas no interior da célula intestina e dependendo do seu sorotipo pode causar várias doenças, como gastroenterites e febre tifoide. Conclusão: Diante do exposto, é possível concluir que a Salmonella spp. está entre os principais agentes envolvidos nas toxinfecções alimentares, é comumente isolada em alimentos de origem avícola (bem como alimentos elaborados à base de ovos) e suinícola, essa transmissão também é ocasionada pela ausência de higiene por parte dos manipuladores, bem como o modo de armazenamento inapropriado dos produtos e consumo de alimentos in natura ou mal-cozidos. 
Palavras-chave: Salmonella spp; Toxinfecções alimentares; Segurança alimentar.

\begin{abstract}
Objective: The objective of the study was to highlight the general characteristics of Salmonella spp. as to pathophysiology, focusing on forms of control and correlating hygiene with food security. Methodology: a search was performed in the bibliographic databases: Science Direct, Google academic, Pubmed and Scielo, to select articles published between the years 2011-2020. The terms used were: Food infections, Salmonella spp., food safety, chicken meat, associated with each other in Portuguese and English. Results: The infectious process by Salmonella spp. it is complex, the bacterium is capable of producing more than 400 proteins that cause inflammatory reactions, even if they are not hosted inside the intestinal cell and depending on its serotype it can cause various diseases, such as gastroenteritis and typhoid fever. Conclusion: In view of the above, it is possible to conclude that Salmonella spp. is among the main agents involved in food toxinfections, is commonly isolated in foods of poultry origin (as well as foods made from eggs) and swine, this transmission is also caused lack of hygiene on the part of handlers, as well as the improper storage of products and consumption of fresh or undercooked food.
\end{abstract}

Keywords: Salmonella spp; Food poisoning; Food security.

\title{
Resumen
}

Objetivo: El objetivo del estudio fue resaltar las características generales de Salmonella spp. en cuanto a fisiopatología, centrándose en formas de control y correlacionando la higiene con la seguridad alimentaria. Metodología: se realizó una búsqueda en las bases de datos bibliográficas: Science Direct, Google académico, Pubmed y Scielo, para seleccionar artículos publicados entre los años 2011-2020. Los términos utilizados fueron: Infecciones alimentarias, Salmonella spp, seguridad alimentaria, carne de pollo, asociados entre sí en portugués e inglés. Resultados: El proceso infeccioso por Salmonella spp. es compleja, la bacteria es capaz de producir más de 400 proteínas que provocan reacciones inflamatorias, aunque no estén alojadas en el interior de la célula intestinal y dependiendo de su serotipo puede provocar diversas enfermedades, como gastroenteritis y fiebre tifoidea. Conclusión: En vista de lo anterior, es posible concluir que Salmonella spp. se encuentra entre los principales agentes involucrados en las infecciones por toxinas alimentarias, es comúnmente aislado en alimentos de origen avícola (así como alimentos elaborados a partir de huevos) y porcinos, esta transmisión también provocó falta de higiene por parte de los manipuladores, así como el almacenamiento inadecuado de los productos y el consumo de alimentos frescos o poco cocidos.

Palabras clave: Salmonella spp; Intoxicación alimentaria; Seguridad alimentaria.

\section{Introdução}

As doenças causadas por alimentos estão entre os principais problemas de saúde pública, encontram-se presentes de forma frequente no cenário de países desenvolvidos como também subdesenvolvidos, denotando uma taxa alta de morbimortalidade. São ocasionadas pela ingestão de alimentos contaminados por microrganismos patogênicos, substâncias químicas e toxinas microbianas (Bernardes e. al., 2018).

Os alimentos comportam-se como substratos que contribuem para a proliferação de microrganismos, e são verdadeiros meios de cultura para as bactérias. O gênero Salmonella spp. é caracterizado por ser um dos principais agentes causadores de Doenças Transmitidas por Alimentos (DTA’s) (Silva et al., 2018).

O gênero Salmonella foi designado em 1885, tendo sua denominação em homenagem ao patologista Daniel Salmon. Integrante da família Enterobacteriaceae, possui bacilos não formadores de esporos, flagelados na maioria das vezes, anaeróbios facultativos, gram negativos, além disso, fermentam a glicose, outros açúcares e descarboxilam aminoácidos, como a lisina (Santos et al., 2013).

O gênero causa três grupos de doenças: febre tifóide (Salmonella typhi), febres entéricas (Salmonella paratyphi) e as enterocolites (demais Salmonellas). O gênero Salmonella é formado por duas espécies principais: Salmonella entérica e Salmonella bongori. As cepas mais recorrentes nas patologias humanas são as de $S$. entérica subsp. entérica, que tem como habitat os animais de sangue quente e correspondem por 99\% das salmoneloses humanas (Silva et al., 2018).

A Salmonelose é a mais preocupante entre as DTA's para a saúde pública em todo o mundo, por seu aspecto endêmico e seu controle depende especificamente da ação humana, uma vez que o homem pode ser propagador do agente etiológico. A segurança dos alimentos tem sido constantemente pauta de discussão em estudos, apresentando relevância para o 
consumidor, fornecedor e fabricante que têm como objetivo ofertar produtos que não provoquem danos à saúde (Silva et al., 2018).

A forma mais recorrente da infecção por Salmonella é a gastroenterite aguda. O período de incubação apresenta variação entre 4 horas a 72 horas após a ingestão de água e alimentos contaminados. Os sintomas iniciais são febre aguda, náuseas, calafrios, vômito, cólicas abdominais e diarreia. Na ocorrência de febre, geralmente desaparece em 72 horas. A diarreia apresenta duração de 3 a 7 dias, de forma autolimitada e geralmente é sanguinolenta.

Em média após 5 semanas a Salmonella é expelida nas fezes. A bacteremia costuma ocorrer apenas em 5 a $10 \%$ das pessoas infectadas, evoluindo para infecção fecal, como infecção óssea, articular e meningite. Pacientes que apresentam o sistema imunológico comprometido, possuem maior propensão a ter infecções por Salmonella prolongada ou recorrente (Cosby et al., 2015).

Tendo em vista os riscos que esse patógeno provoca à saúde pública, o objetivo dessa revisão é evidenciar as características gerais da Salmonella spp. quanto à fisiopatologia, dando enfoque nas formas de controle e correlacionar a higiene com a segurança alimentar.

\section{Metodologia}

O presente trabalho trata-se de uma revisão descritiva com abordagem qualitativa. Nesta metodologia, deu-se início com a escolha de uma questão que norteou a pesquisa. Sendo assim, esta primeira etapa teve grande relevância no desenvolvimento da revisão, pois o tema central é delimitado claramente e de forma específica, objetivando um estudo focado e completo com conclusões de fácil compreensão. Portanto, essa pesquisa teve como questão norteadora: Quais os impactos causados pelo Gênero de bactérias Salmonella na saúde pública e animal?

Após esclarecer a problemática da pesquisa, veio à coleta de dados, nessa etapa ocorre à busca das melhores evidências dentro da literatura, isso inclui a procura por artigos inéditos dentro das bases de dados com finalidade descobrir referências que vão ao encontro do tema apresentado. Assim, escolheu-se a maior quantidade de fontes que se referem com o assunto em questão da pesquisa, servindo para aprofundamento e continuidade do estudo. As buscas foram realizadas em quatro bases de dados: Science Direct, Google acadêmico, Pubmed e Scielo, sendo selecionado artigos publicados entre os anos de 2011 a 2020.

A pesquisa foi desenvolvida com o intuito de encontrar artigos que contenham noções sobre toxinfecções alimentares por Salmonella. A busca foi realizada com os termos: Infecções alimentares, Salmonella, segurança alimentar e carne de frango, associados entre si nos idiomas português e inglês. Na realização do estudo foram utilizadas dezenove referências, envolvendo artigos de revisão, artigos de pesquisa de campo e artigos publicados em anais de evento, todos com acesso aberto. Foram excluídos os arquivos de enciclopédias, resumos e capítulos de livros.

\section{Resultados e Discussão}

No Quadro 1 estão expostos os 11 artigos selecionados nas Bases de dados. 
Quadro 1 - Principais estudos encontrados sobre a gastroenterite Salmonella no organismo humano.

\begin{tabular}{|c|c|c|c|}
\hline Autores & País/Ano & Tipo de estudo & Principais achados \\
\hline Da Silva et al. & Brasil/2019 & Artigo de revisão & $\begin{array}{l}\text { As Salmonelas possuem uma temperatura ideal de } \\
\text { crescimento, sendo } 35^{\circ} \mathrm{C} \text {, podem resistir à dissecação e } \\
\text { ao congelamento, podendo sobreviver a meses ou anos. } \\
\text { As doenças provocadas pelas salmonelas são } \\
\text { consideradas problemas de saúde pública em países } \\
\text { desenvolvidos e em desenvolvimento. Elas são bastante } \\
\text { difundidas geograficamente por todo o mundo, sendo } \\
\text { seu principal habitat o intestino de humanos e animais. }\end{array}$ \\
\hline Dos Santos et al. & Brasil/2013 & Artigo de revisão & $\begin{array}{l}\text { Pode-se diferenciar os sorotipos de acordo com os } \\
\text { antígenos somáticos (O), capsulares (Vi) e flagelares } \\
\text { (H). Existem espécies não especificas das salmonelas } \\
\text { que podem colonizar o trato gastrointestinal de } \\
\text { diferentes espécies. A via oral é a principal fonte de } \\
\text { infecção, entretanto, por aerossol também é encontrada. } \\
\text { O governo possui um papel fundamental na redução das } \\
\text { salmoneloses, com isso deve criar programas para que } \\
\text { ocorra um maior controle na qualidade dos produtos } \\
\text { alimentícios. }\end{array}$ \\
\hline $\begin{array}{l}\text { Domingos, Brunelli } \\
\text { \& Baldotto }\end{array}$ & Brasil/2015 & Artigo de revisão & $\begin{array}{l}\text { Existe uma espécie de Salmonella que raramente é } \\
\text { encontrada em humanos, geralmente só se ver ela em } \\
\text { animais. O período de incubação antes do aparecimento } \\
\text { dos sinais gira em torno de } 6 \text { a } 48 \text { horas. É necessária } \\
\text { uma grande quantidade de patógeno para causar uma } \\
\text { infecção, cerca de } 100.000 \text {. As Salmonellas podem } \\
\text { aderir às superfícies formando um biofilme. Acredita-se } \\
\text { que o abuso de antibióticos pode influenciar na } \\
\text { capacidade de resistência desses patógenos. }\end{array}$ \\
\hline Chen et al. & China/2013 & Artigo de revisão & $\begin{array}{l}\text { O artigo traz informações a respeito da infecção por } \\
\text { Salmonella em humanos, como o período de incubação, } \\
\text { os sintomas de iniciais, quando os mesmos } \\
\text { desaparecem, quando ocorre a excreção da Salmonella } \\
\text { após a infecção. O artigo também relata a possibilidade } \\
\text { da transformação inicial se tornar uma meningite ou } \\
\text { infecção articular e óssea. }\end{array}$ \\
\hline $\begin{array}{l}\text { Machado, Almeida } \\
\text { \& Scheraiber }\end{array}$ & Brasil/2015 & Artigo de revisão & 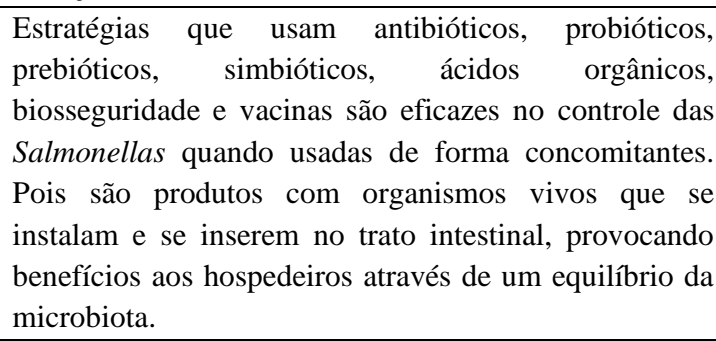 \\
\hline Trainotti et al & Brasil/2013 & $\begin{array}{l}\text { Pesquisa } \\
\text { campo }\end{array}$ & $\begin{array}{l}\text { Foi investigado a presença de Salmonella em } 50 \\
\text { frangos de cortes. Sendo que não foram encontrados } \\
\text { nenhum resquício de sorotipo positivo, sugerindo que } \\
\text { as granjas e abatedouros estão controlando e } \\
\text { prevenindo infecções por meio de higiene adequada. } \\
\text { Para controlar essas infecções não se pode realizar } \\
\text { intervenções apenas na indústria, mas também no } \\
\text { campo, visto que muitas vezes a alimentação é um fator } \\
\text { que contribui para a infecção. }\end{array}$ \\
\hline Pulido-Landínez & EUA/2019 & Artigo de revisão & $\begin{array}{l}\text { O artigo traz a informações a respeito da diversidade } \\
\text { dos sorotipos de Salmonella, muitos não identificados } \\
\text { totalmente, e o quanto isso influencia em termos de } \\
\text { saúde pública e animal. A variedade de hospedeiros e } \\
\text { as várias fontes de infecção tornando a prevenção } \\
\text { deficiente. Como muitos sorotipos não são } \\
\text { identificados, a indústria avícola sofre com uma }\end{array}$ \\
\hline
\end{tabular}




\begin{tabular}{|c|c|c|c|}
\hline & & & $\begin{array}{l}\text { possível disseminação de } \\
\text { transmitidos por alimentos. }\end{array}$ \\
\hline Cosby et al. & EUA/2015 & Artigo de revisão & $\begin{array}{l}\text { As Salmonellas foram responsáveis por } 1.335 \text { surtos } \\
\text { transmitidos por alimentos e } 36.490 \text { doenças } \\
\text { relacionadas a esses surtos nos anos de } 1999 \text { a } 2008 \text {. As } \\
\text { aves domésticas são o maior responsável por essas } \\
\text { infecções comparando com outros produtos } \\
\text { alimentares. }\end{array}$ \\
\hline Bernades et al. & Brasil/2018 & Artigo de revisão & $\begin{array}{l}\text { O artigo fala um pouco sobre os tipos de Salmonelas e } \\
\text { suas doenças, como a febre tifoide, entérica e } \\
\text { gastroenterite. A Salmonella typhi que é a causadora da } \\
\text { febre tifoide, doença que afeta apenas os humanos e } \\
\text { pode se tornar uma grande fonte de infecção, visto que } \\
\text { a bactéria é transportada pelos vasos e pode afetar } \\
\text { órgãos nobres. A Salmonella paratyphi causa a febre } \\
\text { entérica. Para fazer o diagnóstico nos humanos a } \\
\text { respeito das infecções por Salmonella devem ser } \\
\text { levados em consideração alguns fatores como os sinais } \\
\text { clínicos, período de incubação e tipos de alimentos } \\
\text { ingeridos. O tratamento dessas infecções consiste em } \\
\text { aliviar os sintomas com a reidratação e uso de } \\
\text { analgésicos e antitérmicos. }\end{array}$ \\
\hline Soncini & Brasil/2011 & Artigo de revisão & $\begin{array}{l}\text { Ele traz em seu estudo medidas preventivas para } \\
\text { diminuir as infecções por Salmonella em aves, dentre } \\
\text { elas pode-se citar o alojamento de aves que não tenham } \\
\text { nenhum tipo de infecção, verificação da ração que essas } \\
\text { aves consomem, verificar higiene e instalações das } \\
\text { granjas, fazer a verificação bacteriológica das aves } \\
\text { periodicamente, entre outras medidas que podem ser } \\
\text { eficazes na prevenção de infecção das aves e, } \\
\text { consequentemente, das pessoas. }\end{array}$ \\
\hline $\begin{array}{c}\text { Uyttendaele, De } \\
\text { Boeck \& Jacxsens }\end{array}$ & Bélgica/2016 & $\begin{array}{l}\text { Pesquisa } \\
\text { campo }\end{array}$ & $\begin{array}{l}\text { O artigo traz informações a respeito das infecções por } \\
\text { Salmonella, entretanto, seu foco principal é na intenção } \\
\text { que as autoridades têm de conter essas infecções. Existe } \\
\text { um grande interesse em criar planos de contenção com } \\
\text { a criação de medidas eficazes que consistem no } \\
\text { monitoramento, em realização de testes, no transporte, } \\
\text { armazenamento e preparação dos alimentos. }\end{array}$ \\
\hline
\end{tabular}

Fonte: Autores (2021).

A Salmonella é um microrganismo que pode ser encontrado frequentemente em alimentos. Essa bactéria pode estar presente em animais, assim como em produtos originários deles. Durante o pós-abate e o manuseio há riscos de contaminação, inclusive esse microrganismo pode se espalhar por contaminação cruzada com outros tipos de alimentos (Uyttendaele et al., 2016)

Além disso, o homem pode se tornar portador após uma infecção por Salmonella, e assim ser disseminador dessa bactéria. Sendo assim, suas ações na hora da preparação de um alimento podem ou não favorecer a contaminação desse produto. Além do mais, tal patógeno pode se adaptar a uma variedade de animais e ambientes, assim como, sobreviver em períodos que variam de meses a anos, o que torna os hábitos de higiene ainda mais indispensáveis (Silva et al., 2019).

A limpeza inadequada de frutas e vegetais, bem como o costume de não higienizar as mãos durante a preparação de alimentos são os hábitos mais indicados como causadores de incidência da infecção. Sendo assim, os manipuladores têm um papel essencial na redução dos riscos de salmoneloses, pois, é de extrema importância que se tenha o controle de todas as etapas de preparação, desde a recepção da matéria-prima até o consumo do alimento (Leite et al., 2019) 
Para Aljindan \& colaboradores (2020) a Salmonela é transmitida aos seres humanos por meio de alimentos de origem animal, e isso constitui um reservatório para o patógeno. Dentre as principais fontes que favorecem essa transmissão estão as cabras, gado, camelos, ovelhas e peixes. No entanto, ainda é possível que ocorra através de outras fontes alimentares, como vegetais e frutas. Esta bactéria possui uma grande variedade de hospedeiros, segundo o estudo de Pulido-Landínez (2019), sendo os sorotipos de maior relevância aqueles que não estão restritos a uma única espécie, afetando tanto humanos como animais (Salmonella zoonótica).

No que diz respeito a complicações, o estudo de Aljindan \& colaboradores (2020) traz como principal manifestação clínica a gastroenterite, que pode ser causada por Salmonella não tifoidal, Salmonella typhi e Salmonella paratyphi (Salmonella tifoidal). Com exceção da primeira, estas são consideradas patógenos restritos ao homem e só podem ser transmitidos entre humanos. A forma mais branda é a Salmonelose, desenvolvida com o cruzamento da mucosa intestinal até a corrente sanguínea, infectando órgãos profundos, como ossos e articulações. Certamente, suas características endêmicas e alta morbilidade fazem desta uma ameaça à saúde pública, necessitando de uma atenção clínica.

A pesquisa de Gand e colaboradores (2020) confirma a mesma ideia, citando que a Salmonelose pode resultar em sintomas não invasivos, como gastroenterite, ou em sintomas invasivos mais perigosos, como febre e bacteremia, podendo levar na ausência de tratamento o indivíduo a óbito. O estudo enfatiza ainda a variedade de animais produtores de alimentos que podem ser contaminados, como aves, porcos e gado, fazendo destes os principais reservatórios de Salmonella.

De acordo com o exposto por Zhang e Col. (2020) a contaminação de alimentos e rações por Salmonella contribui para sérias perdas econômicas e problemas saudáveis em todo o mundo, como gastroenterites e doenças diarreicas relacionadas a lesões ileais e distúrbios da flora intestinal. A pesquisa apresentou ainda que distúrbios na microbiota intestinal, ou disbiose, pode desencadear a progressão de várias patologias, em virtude de o intestino ficar suscetível a ataques de radicais livres excessivos, resultando em metabolismo anormal das células epiteliais intestinais, na função celular prejudicada e em reação inflamatória.

Se tratando de sintomas, Soncini (2011) diz que dos mais de 2000 sorovares descritos, poucos são associadas a produção de doenças no hospedeiro, caracterizada por quadros de diarreia, febre e vômitos, podendo levar a septicemia e morte. Dentre os sorovares espécie-específica considerados exceção no processo de colonização do intestino pode-se mencionar a Salmonella gallinarum nas aves, S. typhi em humanos e $S$. cholerasuis nos suínos.

Em relação à fisiopatologia, Silva et al. (2019) descreve que após a ingestão de um alimento contaminado com Salmonella, estas atravessam a camada epitelial intestinal e ao alcançar a lâmina própria (camada em que as células epiteliais estão apoiadas), proliferam. Posteriormente, são fagocitadas pelos monócitos e macrófagos, provocando resposta inflamatória, devido à hiperatividade do sistema reticuloendotelial. Nas enterocolites, ao contrário do que acontece na febre tifóide, a penetração de Salmonella spp. fica restrita à lâmina própria e dificilmente se observa septicemia ou infecção sistêmica, ficando a infecção limitada à mucosa intestinal.

De acordo com Ferreira et al. (2013) a resposta inflamatória também está associada com a liberação de prostaglandinas. Estas estimulam a Adenil ciclase, enzima que catalisa a hidrolise de ATP, o que resulta em aumento da secreção de água e eletrólitos, causando diarreia aquosa, dor abdominal, deficiência de eletrólitos e desidratação, fator este que provoca dor de cabeça e cansaço. A liberação de pirógenos pelas células de defesa provoca a febre.

O processo infeccioso por Salmonella spp. é bem mais complexo do que aparenta. Essa bactéria é capaz de produzir mais de 400 proteínas que provocam reações inflamatórias, mesmo que não estejam hospedadas no interior da célula intestinal. Dessa forma, esse patógeno tem a capacidade de provocar sintomas mesmo que se encontre no meio extracelular e dependendo do seu sorotipo pode causar várias doenças, como gastroenterites e febre tifoide (Carneiro \& Costa, 2020). 


\section{Conclusão}

Diante do exposto, foi possível verificar que a Salmonella spp está entre os principais agentes envolvidos nas toxinfecções alimentares, é comumente isolada em alimentos de origem avícola (bem como alimentos elaborados a base de ovos) e suinícola, essa transmissão também é ocasionada pela ausência de higiene por parte dos manipuladores, bem como o modo de armazenamento inapropriado dos produtos e consumo de alimentos cru ou mal cozido.

Portanto, essa bactéria possui alto poder de virulência, sendo abundantemente distribuído na natureza de fácil contaminação, contudo de difícil eliminação desafiando assim o setor industrial a adotar medidas de prevenção e controle mais rigorosas desse agente, a fim de diminuir os problemas de salmoneloses, com a busca de métodos eficientes, de práticas higiênico sanitárias adequadas no processamento, cuidados na manipulação (bem como a própria higiene dos manipuladores), conservação e consumo de alimentos, como também a implantação de sistemas de controle de qualidade microbiológica.

Assim, os resultados expostos na pesquisa reforçam o quanto a higiene adequada é fundamental, principalmente no âmbito alimentar. Além dos cuidados higiênicos realizados pelas indústrias por parte dos manipuladores também há necessidade da higienização doméstica, como a limpeza correta dos alimentos, armazenamento e modo de conservação dos mesmos, bem como a limpeza dos utensílios e local de preparação, assim como os cuidados higiênicos durante o modo de preparo das refeições, isto consequentemente evita tanto a contaminação direta, quanto a contaminação cruzada entre alimentos crus e cozidos.

\section{Referências}

Aljindan, R. Y., \& Alkharsah, K. R. (2020). Pattern of increased antimicrobial resistance of Salmonella isolates in the Eastern Province of KSA. Journal of Taibah University Medical Sciences, 15(1), 48-53. https://doi.org/10.1016/j.jtumed.2019.12.004

Bernardes, N. B., Facioli, L. D. S., Ferreira, M. L., Costa, R. D. M., \& Sá, A. C. F. de. (2018). Intoxicação Alimentar: Um problema de Saúde Pública. Id on Line Revista de psicologia, 12(42), 894-906. https://doi.org/10.14295/idonline.v12i42.1373

Carneiro, D. O., \& Costa, M. S. F. (2020). Características e patogenicidade da salmonella enterica: uma revisão de literatura. Visão acadêmica, Curitiba, $21(1), 72-79$.

Chen, H. M., Wang, Y., Su, L. H., \& Chiu, C. H. (2013). Nontyphoid Salmonella infection: Microbiology, clinical features, and antimicrobial therapy. Pediatrics and Neonatology, 54(3), 147-152. https://doi.org/10.1016/j.pedneo.2013.01.010

Cosby, D. E., Cox, N. A., Harrison, M. A., Wilson, J. L., Jeff Buhr, R., \& Fedorka-Cray, P. J. (2015). Salmonella and antimicrobial resistance in broilers: A review. Journal of Applied Poultry Research, 24(3), 408-426. https://doi.org/10.3382/japr/pfv038

Da Silva, A. J. H., dos Anjos, C. P., da Silva Nogueira, L., Ribeiro, A. C. R., \& Fraga, E. G. S. (2019). Salmonella spp. um agente patogênico veiculado em alimentos. Encontro de Extensão, Docência e Iniciação Científica (EEDIC), 5(1).

Domingos, I., Brunelli, S. R., \& Baldotto, S. B (2015). Salmonella spp. - uma revisão. Revista FAIT, $2(3) .15$.

Dos Santos, J. R., Meza, S. K. L., Martini, K. C., \& Nunes, R. V. (2013). A importância do controle da salmonella na cadeia produtiva de frangos de corte. Scientia Agraria Paranaensis, 12 (3), 167 a 174. https://doi.org/10.18188/sap.v12i3.6777

Ferreira, Lídia Lopes; Mendes, Fernanda Rodrigues; Santos, Bruno Moreira dos; Andrande, Maria Auxiliadora; \& Café, M. B. (2013). Salmonelose em sanidade avícola e saúde pública. In Revista eletrônica Nutritime, 10(5), 2716-2751). https://www.nutritime.com.br/arquivos_internos/artigos/artigo_213.pdf

Gand, M., Mattheus, W., Roosens, N., Dierick, K., Marchal, K., Bertrand, S., \& De Keersmaecker, S. C. J. (2020). A genoserotyping system for a fast and objective identification of Salmonella serotypes commonly isolated from poultry and pork food sectors in Belgium. Food Microbiology, 91, 103534. https://doi.org/10.1016/j.fm.2020.103534

Leite, D. S, Oliveira, A. S., Monteiro, A. C. G., \& Santos, J. F (2019). Educação em saúde para a prevenção de salmonelose com manipuladores de alimentos em Manaus, Amazonas, Brasil. Nexus- Revista de Extensão do IFAM, (9), 33-42.

Machado, M. S., de Almeida, G. C., \& Scheraiber, M. (2015). Controle da infecção por Salmonella Enterica Sorovar Enteritidis em frangos de corte suplementados com probióticos. Revista eletrônica biociências, biotecnologia e saúde, 3(12), 127-128.

Pulido-Landínez, M. (2019). Food safety - Salmonella update in broilers. Animal Feed Science and Technology, 250, 53-58. https://doi.org/10.1016/j.anifeedsci.2019.01.008

Santos, J. R., Meza, S. K. L., Martini, K. C., \& Nunes, R. V. (2013). A Importância do Controle da Salmonella na Cadeia Produtiva de Frango de Corte. Scientia Agraria Paranaensis, 12(3), 167-174. https://doi.org/10.18188/1983-1471/sap.v12n3p167-174 
Research, Society and Development, v. 10, n. 4, e12610413656, 2021

(CC BY 4.0) | ISSN 2525-3409 | DOI: http://dx.doi.org/10.33448/rsd-v10i4.13656

Silva, A. J. H. da, Anjos, C. P. dos, Nogueira, L. da S., Ribeiro, A. C. R., \& Fraga, E. G. S. (2013). Salmonella Spp. Um Agente Patogênico Veiculado Em Alimentos. Climate Change 2013 - The Physical Science Basis, 53(9), 1-30. https://doi.org/10.1017/CBO9781107415324.004

Soncini, R. A. (2011). Controle de Salmonella enteritidis na avicultura. In III SIMPOSIO BRASIL.

Trainotti, A. C., Moraes, F. F., Begotti, I. L., \& Merlini, L. (2013). Ocorrência de Salmonella sp. em cortes de frangos industrialmente processados procedentes de explorações industriais da região noroeste do estado do Paraná-Brasil. Enciclopédia Biosfera, 9(17), 1965-1970.

Uyttendaele, M., De Boeck, E., \& Jacxsens, L. (2016). Challenges in Food Safety as Part of Food Security: Lessons Learnt on Food Safety in a Globalized World. Procedia Food Science, 6(Icsusl 2015), 16-22. https://doi.org/10.1016/j.profoo.2016.02.003

Zhang, L., Gui, S., Wang, J., Chen, Q., Zeng, J., Liu, A., Chen, Z., \& Lu, X. (2020). Oral administration of green tea polyphenols (TP) improves ileal injury and intestinal flora disorder in mice with Salmonella typhimurium infection via resisting inflammation, enhancing antioxidant action and preserving tight junction. Journal of Functional Foods, 64, 103654. https://doi.org/10.1016/j.jff.2019.103654 